
2 2yes.

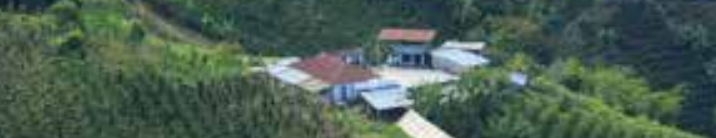




\section{MANEJO AGRONÓMICO DE \\ CULTIVOS INTERCALADOS CON CAFÉ}

Santiago Jaramillo Cardona *

La práctica de sembrar cultivos intercalados en las calles del café durante la etapa de levante fortalece la seguridad alimentaria y nutricional de las familias caficultoras, y constituye una fuente de ingresos durante los meses improductivos del café. Además, genera bienes y servicios ecosistémicos que contribuyen a la sostenibilidad de la finca cafetera.

En el sistema intercalado, el café siempre es el cultivo principal y el cultivo transitorio es el cultivo secundario, por esta razón, el manejo agronómico de ambos debe realizarse de manera independiente para no generar competencia entre los dos cultivos. El intercalamiento de maíz y fríjol es una práctica recomendada principalmente para sistemas de libre exposición y para lotes renovados por siembra o por zoca, en donde pueden llevarse a cabo hasta dos cosechas de maíz y tres cosechas de fríjol arbustivo, durante los primeros 18 meses, antes de obtener la primera cosecha de café.

A continuación, se describen las principales prácticas de manejo agronómico de maíz y fríjol intercalados con café, enfocadas a lograr una mayor productividad y sostenibilidad.

\section{semillas y fecha de siembra}

El material de siembra se refiere a la semilla mejorada (variedad o híbrido) de maíz o fríiol que se va a utilizar para el intercalamiento. Las semillas recomendadas por Cenicafé son previamente evaluadas en las Estaciones Experimentales del Centro para garantizar una amplia adaptabilidad de los materiales a las condiciones propias de la zona cafetera y un buen desempeño productivo bajo el sistema intercalado.

Como ocurre con el café, el uso de semillas genéticamente mejoradas (no transgénicos) es un factor determinante para obtener una alta productividad y calidad del cultivo intercalado. 
En la actualidad los caficultores colombianos pueden acceder a las nuevas semillas de maíz y fríjol de excelente comportamiento agronómico y alta calidad nutricional, que han sido desarrollados a través de convenios entre la Federación Nacional de Cafeteros de Colombia, la alianza CIATBioversity y el programa HarvestPlus; un resultado de estos esfuerzos fue la liberación del primer híbrido de maíz blanco biofortificado con zinc (SGBIOH2), adaptado a las condiciones de la zona cafetera.
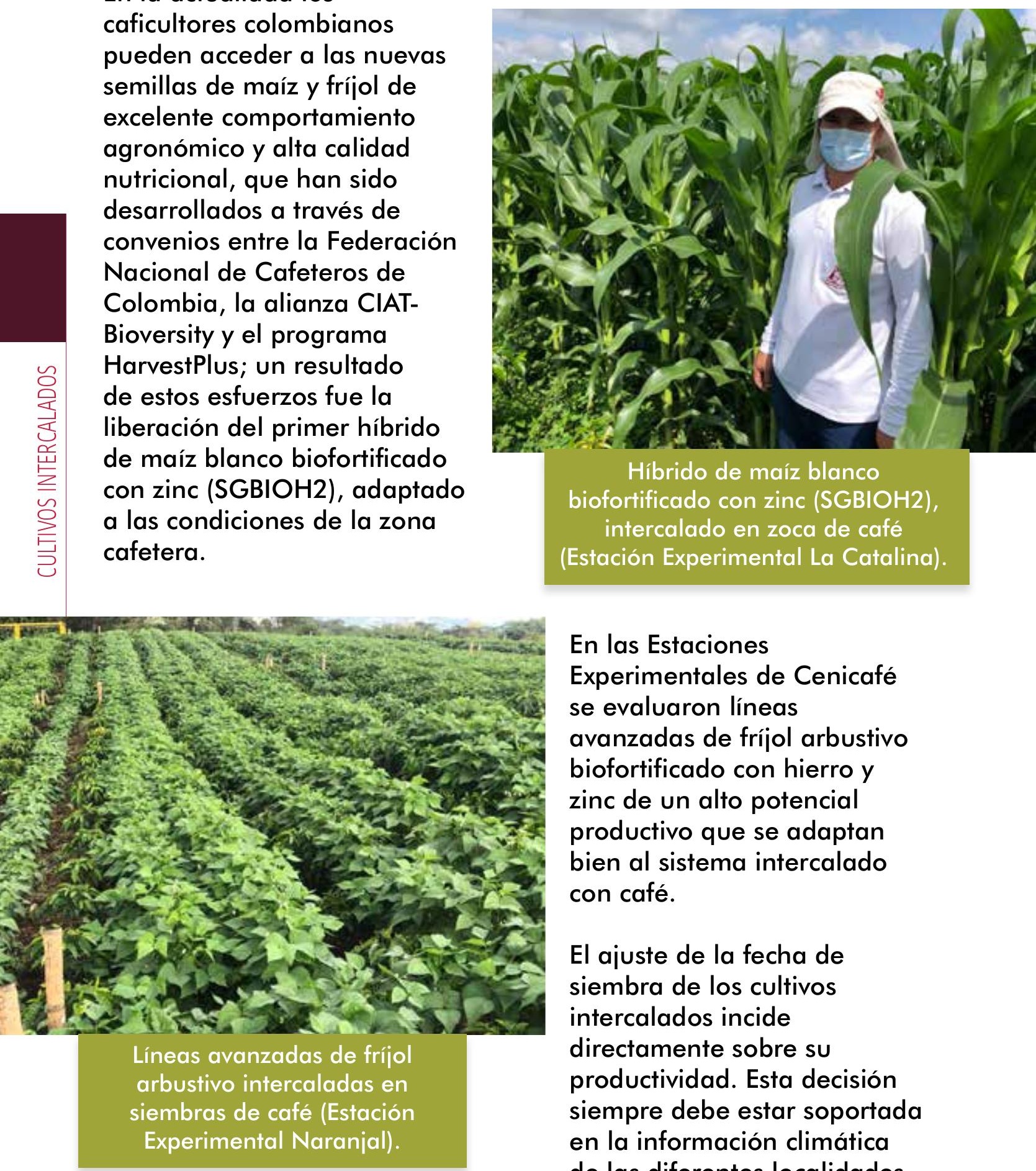

En las Estaciones

Experimentales de Cenicafé se evaluaron líneas avanzadas de fríjol arbustivo biofortificado con hierro y zinc de un alto potencial productivo que se adaptan bien al sistema intercalado con café.

El ajuste de la fecha de siembra de los cultivos intercalados incide directamente sobre su productividad. Esta decisión siempre debe estar soportada en la información climática de las diferentes localidades que está disponible en la 
plataforma Agroclima de Cenicafé (agroclima.cenicafe.org). El análisis del comportamiento histórico de la precipitación permite al caficultor planear la fecha de siembra al inicio de los meses de lluvias para suplir los requerimientos hídricos de los cultivos intercalados, en función de la etapa fisiológica y de la duración del ciclo. En el caso del cultivo de fríjol arbustivo cuyo ciclo es de 90 días, se recomienda ajustar la fecha de siembra para garantizar un adecuado suministro de agua durante los primeros 45 días después de emergencia (etapa vegetativa) y una alta radiación solar desde la etapa de formación de vainas hasta madurez fisiológica (etapa reproductiva), con el propósito de obtener una alta sanidad y cosechar en época seca o de menos lluvias.

\section{Densidad de siembra y arreglos espaciales}

Las densidades de siembra o número de plantas por hectárea de los cultivos intercalados recomendadas por Cenicafé responden a arreglos poblacionales que garantizan la máxima producción del cultivo intercalado, sin que se afecte la producción de café. Mediante un sistema de siembra de surcos dobles ubicados en el centro de las calles del café y distanciados $40 \mathrm{~cm}$ entre ellos, solo basta ajustar el número de plantas por metro lineal, para obtener las poblaciones recomendadas de 55.000 plantas/ha de maíz intercalado y de 160.000 plantas/ha de fríjol arbustivo intercalado.

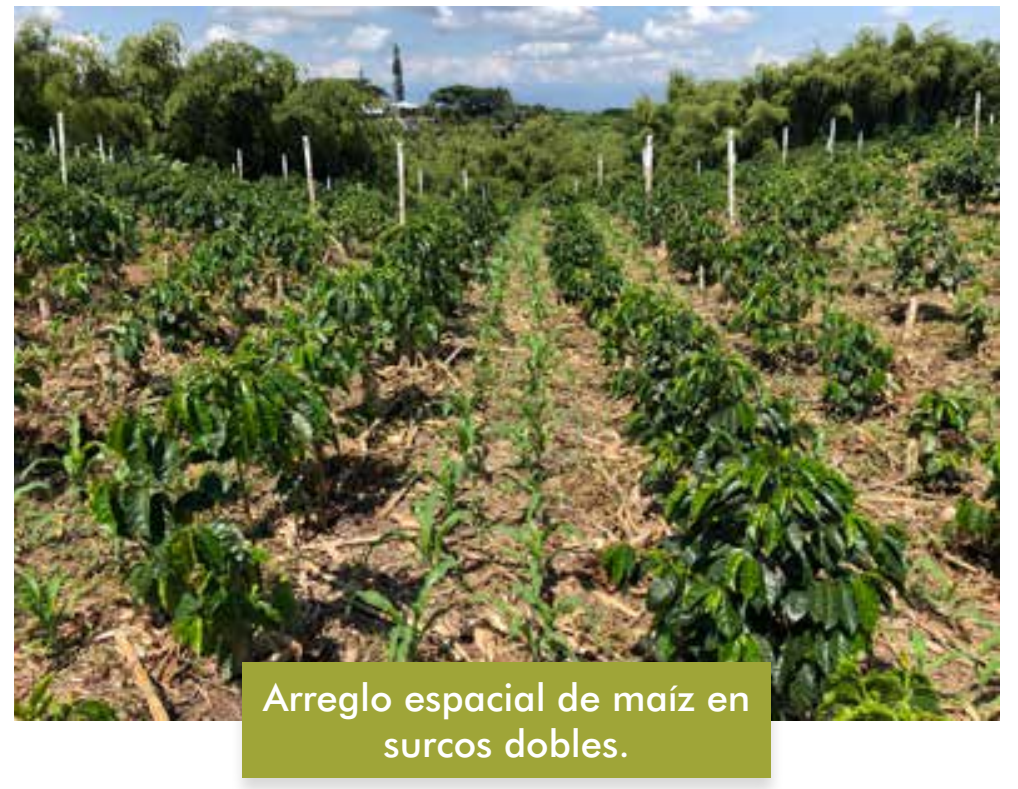




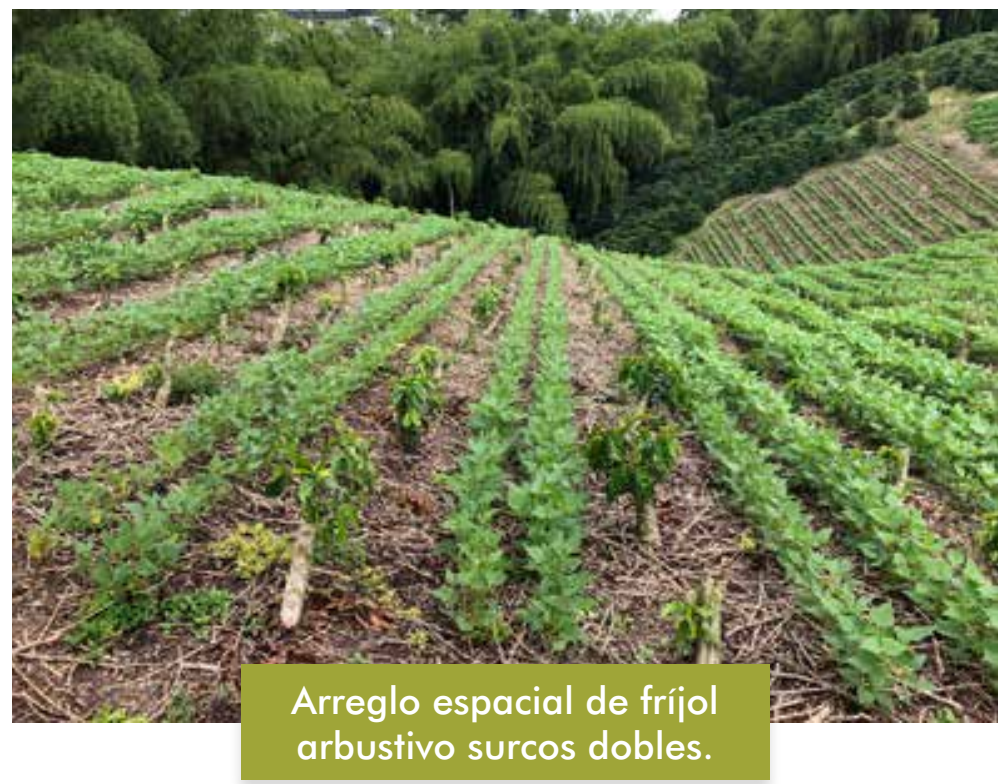

Una vez definida la densidad de siembra del cultivo intercalado debe estimarse la cantidad de semilla, en kilogramos por hectárea, en función del índice de semilla del material a sembrar. Para el maíz, el índice de semilla corresponde al peso en gramos de 1.000 semillas, mientras que para el fríjol corresponde al peso en gramos de 100 semillas. Es importante hacer previamente pruebas de germinación de estas semillas para ajustar la cantidad adicional de semilla en caso de ser necesario.

\section{Manejo integrado de arvenses}

Durante la etapa de establecimiento de los cultivos intercalados en las calles del café, es necesario realizar un manejo oportuno y eficaz de las arvenses, que garantice una buena germinación del maíz/ fríjol y que disminuya la competencia por espacio, nutrientes, luz y agua. Este período crítico de competencia entre las arvenses y el cultivo intercalado ocurre durante los primeros 30 días después de la siembra, de allí la importancia de realizar controles oportunos, que eviten la interferencia y mejoren el establecimiento de las poblaciones recomendadas.

En lotes de café renovados por siembra o por zoca se recomienda el control mecánico en las calles del café, diez días antes de la 
siembra del intercalado. Un día después de sembrar el maíz o el fríjol se recomienda realizar una aplicación con pantalla (para evitar fitotoxicidad en el café), a baja presión (20 psi) de una mezcla de glifosato $(1,5 \mathrm{~L} / \mathrm{ha})$ con pendimetalina $(800 \mathrm{cc} / \mathrm{ha})$, es importante aclarar que esta recomendación aplica para lotes con pendientes inferiores al $40 \%$, ya que el uso de herbicidas pre-emergentes en las calles del café puede favorecer la erosión hídrica. Estas mezclas con productos con registro para café ofrecen excelentes controles, permitiendo tener un cultivo intercalado limpio durante los primeros 25 días y el establecimiento de coberturas de arvenses nobles después de los 30 días de la aplicación.

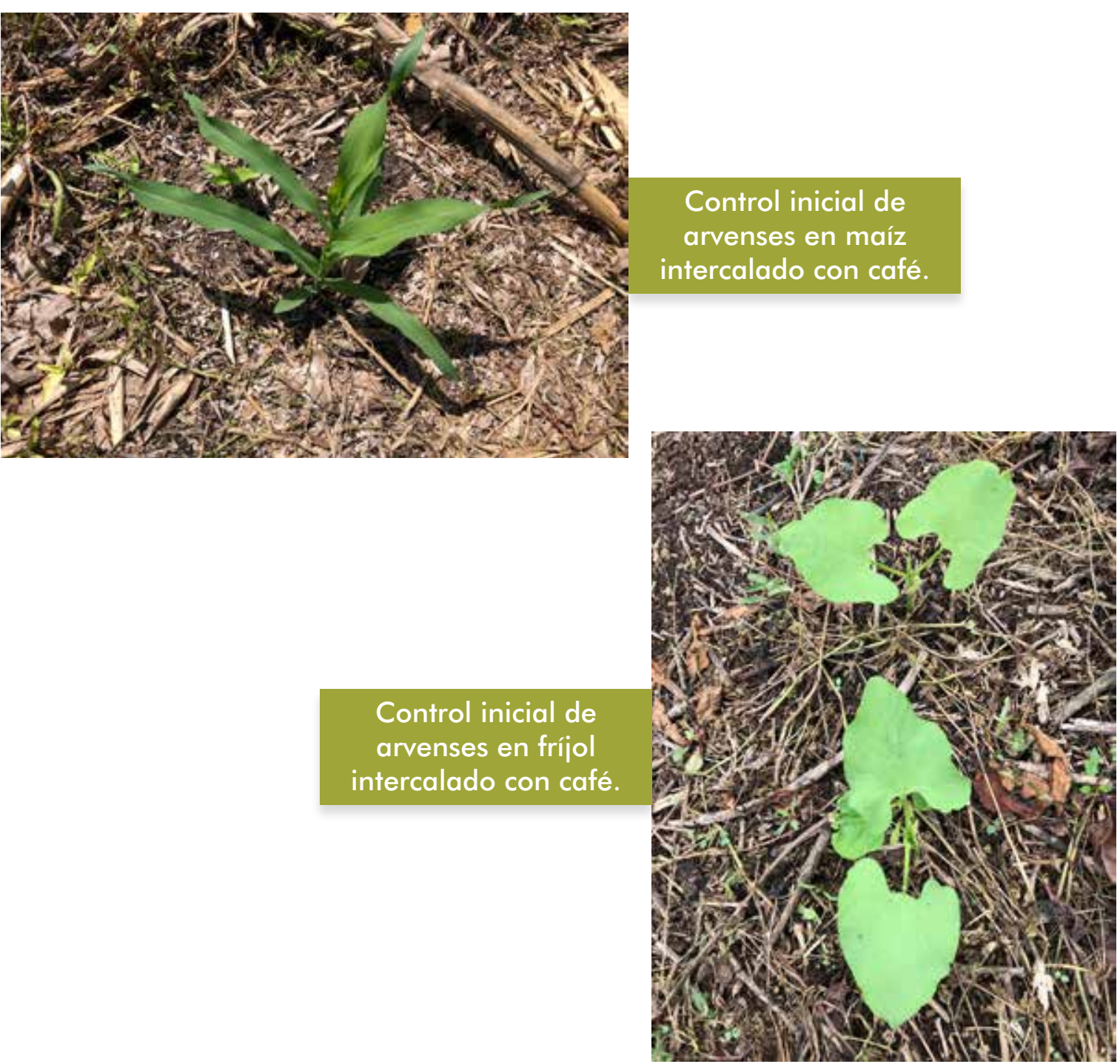


Un mes después de la germinación debe evaluarse el estado de crecimiento de las arvenses para definir la necesidad de controles manual-mecánicos $y$, una vez tanto el maíz como el fríjol han superado esta etapa crítica de competencia, las arvenses dejan de ser una limitante de la productividad.

\section{Manejo de suelos y nutrición}

El manejo sostenible del suelo y de la nutrición de los cultivos intercalados parte del análisis de las propiedades físicas y químicas del suelo. Los cultivos intercalados deben ser manejados mediante un enfoque de agricultura de conservación (labranza mínima), en donde se reduzca la degradación del suelo, se establezcan coberturas de arvenses nobles y se dejen los residuos vegetales sobre la superficie para proteger el suelo mientras se conserva la humedad.

Las propiedades químicas de los suelos de la zona cafetera son propicias para la producción rentable de cultivos intercalados, debido a los altos contenidos de materia orgánica; sin embargo, el $\mathrm{pH}$ ligeramente ácido de estos suelos limita la disponibilidad de algunos elementos como fósforo, potasio, magnesio y calcio, que son esenciales para el desarrollo de estos sistemas. Por esta razón, la determinación previa de la acidez del suelo, mediante el análisis químico, es fundamental para definir la necesidad de enmiendas en las calles del café (30-45 días antes de la siembra), especialmente para el cultivo del maíz.

Para la fertilización del maíz y el fríjol es importante considerar los niveles de extracción de nutrientes, los contenidos determinados en el análisis de suelo y la disponibilidad de humedad de suelo. La fertilización de los cultivos intercalados debe realizarse de manera independiente a la fertilización del café para no generar competencia por nutrientes que afecte la producción de ambos. 
Para el caso del maíz intercalado con café, la fertilización se lleva a cabo, así:

- Ełapa VE - 5 días después de la emergencia de las plantas, se aplica una mezcla por hectárea de $40 \mathrm{~kg}$ de $\mathrm{N}, 100 \mathrm{~kg}$ de $\mathrm{P}_{2} \mathrm{O}_{5}$ y $50 \mathrm{~kg}$ de $\mathrm{K}_{2} \mathrm{O}$ en forma de corona, evitando el contacto directo del fertilizante con los tallos tiernos. En suelos con deficiencias de magnesio, se recomienda la aplicación de Kieserita en dosis de 15 $\mathrm{kg} / \mathrm{ha}$ en el primer abonamiento.

- Etapa V6 - Sexta hoja, se aplica una mezcla por hectárea de 69 kg de $\mathrm{N}$ y $50 \mathrm{~kg}$ de $\mathrm{K}_{2} \mathrm{O}$

- Etapa V10- Décima hoja, se aplican $69 \mathrm{~kg} / \mathrm{ha}$ de $\mathrm{N}$.

Para el caso del fríjol intercalado con café la fertilización se realiza así:

- A los 5 días después de la emergencia se aplica una mezcla por hectárea de $20 \mathrm{~kg}$ de $\mathrm{N}, 15 \mathrm{~kg}$ de $\mathrm{P}_{2} \mathrm{O}_{5}$ y $20 \mathrm{~kg}$ de $\mathrm{K}_{2} \mathrm{O}$ al chorrillo

- Después de 30 días de la emergencia se aplican $20 \mathrm{~kg} / \mathrm{ha}$ de $\mathrm{N}$ al chorrillo en la base de los tallos del fríjol.

Extracción de nutrientes de

maíz y fríjol arbustivo (kg/ha).

\begin{tabular}{|c|c|c|c|c|c|c|}
\hline \multirow{2}{*}{$\begin{array}{c}\text { Cultivo/ } \\
\text { Nutriente }\end{array}$} & \multicolumn{6}{|c|}{ Extracción de nutrientes (kg/ha) } \\
\cline { 2 - 7 } & Nitrógeno & Fósforo & Potasio & Calcio & Magnesio & Azufre \\
\hline Maíz & 187 & 38 & 192 & 38 & 44 & 22 \\
\hline $\begin{array}{c}\text { Frijol } \\
\text { arbustivo }\end{array}$ & 134 & 16 & 116 & 64 & 21 & 23 \\
\hline
\end{tabular}

Manejo integrado de plagas

El manejo integrado de plagas en los cultivos intercalados se fundamenta en combinar prácticas de prevención, monitoreo y control (cultural, biológico y químico), con el objetivo de reducir los daños económicos ocasionados por las principales plagas y disminuir los riesgos para las personas y para el medioambiente.

El tratamiento de las semillas con insecticidas sistémicos, es una práctica recomendada para proteger a las plántulas de maíz y fríjol del ataque de insectos trozadores y tierreros, durante la emergencia, 
y de insectos fitófagos durante el levante (primeros 20 días); y facilitar el establecimiento de las poblaciones de insectos benéficos que actuan como controladores biológicos, ya que no se requiere la aplicación de insecticidas durante las etapas tempranas del cultivo intercalado. En el caso del maíz, el tratamiento de la semilla protege a las plántulas del ataque inicial de Dalbulus maidis (chicharrita) que es el vector de la enfermedad conocida como el complejo del achaparramiento del maíz. En el caso del fríjol, el tratamiento de la semilla reduce la incidencia de daño inicial por insectos chupadores como Bemisia tabaco (mosca blanca), Aphis gossypii (áfidos) y Empoasca kraemeri (lorito verde).

A medida que aumenta el área foliar de los cultivos intercalados también aumenta la presión de los insectos comedores de follaje, como es el caso de Spodoptera frugiperda (gusano cogollero del maíz) y de Epitrix sp., Diabrotica sp y Cerotoma sp. (crisomélidos del fríjol). Para realizar un manejo integrado de Spodoptera se recomienda un monitoreo frecuente, para definir el momento oportuno de control en función del número de lesiones en las hojas y su tamaño. Como una medida efectiva de control biológico de Spodoptera se recomiendan dos liberaciones de Trichogramma sp; la primera liberación en la etapa VE (5 días después de emergencia) y la segunda liberación en la etapa V4 (cuarta hoja), a razón de 50 pulgadas por hectárea en cada una. El uso de insecticidas biológicos a base de Bacillus thurigensis subsp kurstaki, son una excelente alternativa para el manejo de gusano cogollero y ofrecen una efectividad muy similar a los controles obtenidos con insecticidas como el clorpirifos.

\section{Manejo integrado de entermedades}

La sanidad de los cultivos intercalados con café es un requisito indispensable para lograr una mayor productividad y calidad. El manejo integrado de enfermedades incluye el uso de semilla certificada mejorada, con buena adaptación a las condiciones particulares de las distintas localidades, el ajuste de la densidad de siembra para establecer las poblaciones recomendadas por Cenicafé para el sistema intercalado, y el conocimiento de las diferentes enfermedades a través del ciclo del cultivo como de los factores que pueden favorecer la proliferación de enfermedades (condiciones de 
suelo, fecha de siembra, manejo del nitrógeno, estado de crecimiento de las arvenses, factores ambientales, manejo de residuos de cosecha, entre otros).

Las semillas de maíz (híbridos o variedades) recomendadas para el sistema intercalado con café deben presentar tolerancia a las principales enfermedades fungosas de la zona cafetera como es el caso de Helminthosporium sp. (quemazón), Cercospora sp. (mancha gris), Phyllacora maydis (mancha de asfalto), Puccinia polysora (roya), Physoderma sp. (mancha café o peca). Para el caso del fríjol se recomienda la siembra de variedades con tolerancia a enfermedades como pudriciones radiculares ocasionadas por hongos del suelo como Fusarium oxysporum, Rhizoctonia solani, Macrophomina phaseolina y Pythium spp; $y$ enfermedades foliares como Thanatephorus cucumeris (mustia hilachosa), Colletotrichum lindemuthianum (antracnosis), Phaeoisariopsis griseola (mancha angular), Uromyces appendiculatus (roya), Sclerotinia sclerotiorum (moho blanco), Xanthomonas campestris pv. phaseoli (bacteriosis) y virus del mosaico común del fríjol (BCMV). Las estrategias de manejo integrado de las diferentes enfermedades de los cultivos intercalados deben estar soportadas en el monitoreo constante y en las recomendaciones sugeridas por el servicio de Extensión.

\section{Cosecha}

Existen varios indicadores que puede usar el caficultor al determinar el momento oportuno para cosechar el maíz y el fríjol intercalado. La humedad de grano es la medida más usada para definir cuándo cosechar, consiste en tomar muestras de granos a los que se les determina su humedad con la ayuda de un medidor. Para el caso del maíz, el rango de humedad de grano para cosecha oscila entre $20 \%$ $25 \%$ de humedad, mientras que para el fríjol la humedad de cosecha es del $20 \%$.

Otra forma para determinar el punto de madurez de cosecha son los días después de siembra. El ciclo de un material se refiere al tiempo que transcurre desde la siembra hasta la cosecha de grano seco, y depende de factores genéticos y ambientales. 
Para la zona cafetera colombiana se recomiendan cultivares de maíz cuyo ciclo oscila entre los 145 a 160 días y cultivares de fríjol cuyo ciclo es de 90 días. Si el propósito de la producción de maíz es la comercialización de mazorcas tiernas (choclo), la cosecha manual debe realizarse cerca de los 90 días después de siembra en estado de grano lechoso.

Los cambios en la apariencia del grano también se utilizan como método empírico, comúnmente utilizado por los agricultores para determinar el momento de la cosecha. Para el caso del maíz, la desaparición de la línea de leche y la aparición del punto negro en los granos son indicadores de madurez fisiológica.

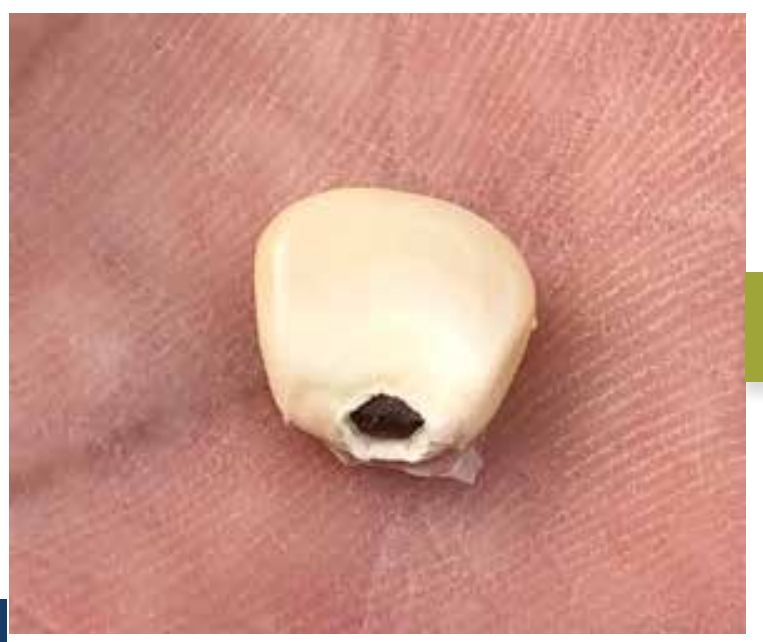

Punto negro en granos de maíz. 


\section{Poscosecha}

Después de la cosecha, tanto al maíz como al fríjol se les realizan seis prácticas de beneficio que incluyen: desgrane, pre-secado, limpieza, secado, empaque y almacenamiento.

El desgrane de las mazorcas de maíz puede realizarse de manera manual o con desgranadora mecánica, mientras que el desgrane del fríjol puede realizarse mediante un golpeo mecánico con palos de madera (aporreo de vainas secas), sobre una lona o con la ayuda de una desgranadora mecánica.

El pre-secado se realiza para disminuir la humedad y para facilitar la remoción de impurezas de la masa recolectada.

La limpieza de grano consiste en una separación física de las impurezas (tusa, afrecho, gavilla, semillas de arvenses) por medio de una corriente de aire suministrada por un ventilador.

El secado de los granos de maíz o fríjol puede realizarse en secadores parabólicos hasta que la masa de grano presente una humedad cercana al $14 \%$. Mientras que el gradiente de secado del maíz en un secador parabólico disminuye aproximadamente un $1 \%$ de humedad por día, el fríjol solo necesita de uno a dos días para bajar de $20 \%$ a $14 \%$. Una vez los granos presenten una humedad inferior al $16 \%$ de humedad pueden empacarse en costales de fibra y almacenarse sobre estibas de madera en un lugar fresco y seco. 


\section{Gultivos

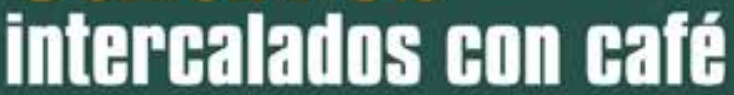

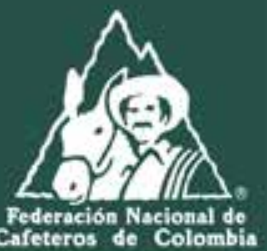

Fl maiz y frijol se siembran intercalados en las calles de lotes renovados por zoca común o por siembra

Fll plátano se establece en forma de barreras

Debe hacerse un manejo independiente de ambos cultivos para que la T- producción de cafe no se afecteal intercalar dos ciclos de maiz o frijol

caficultor:
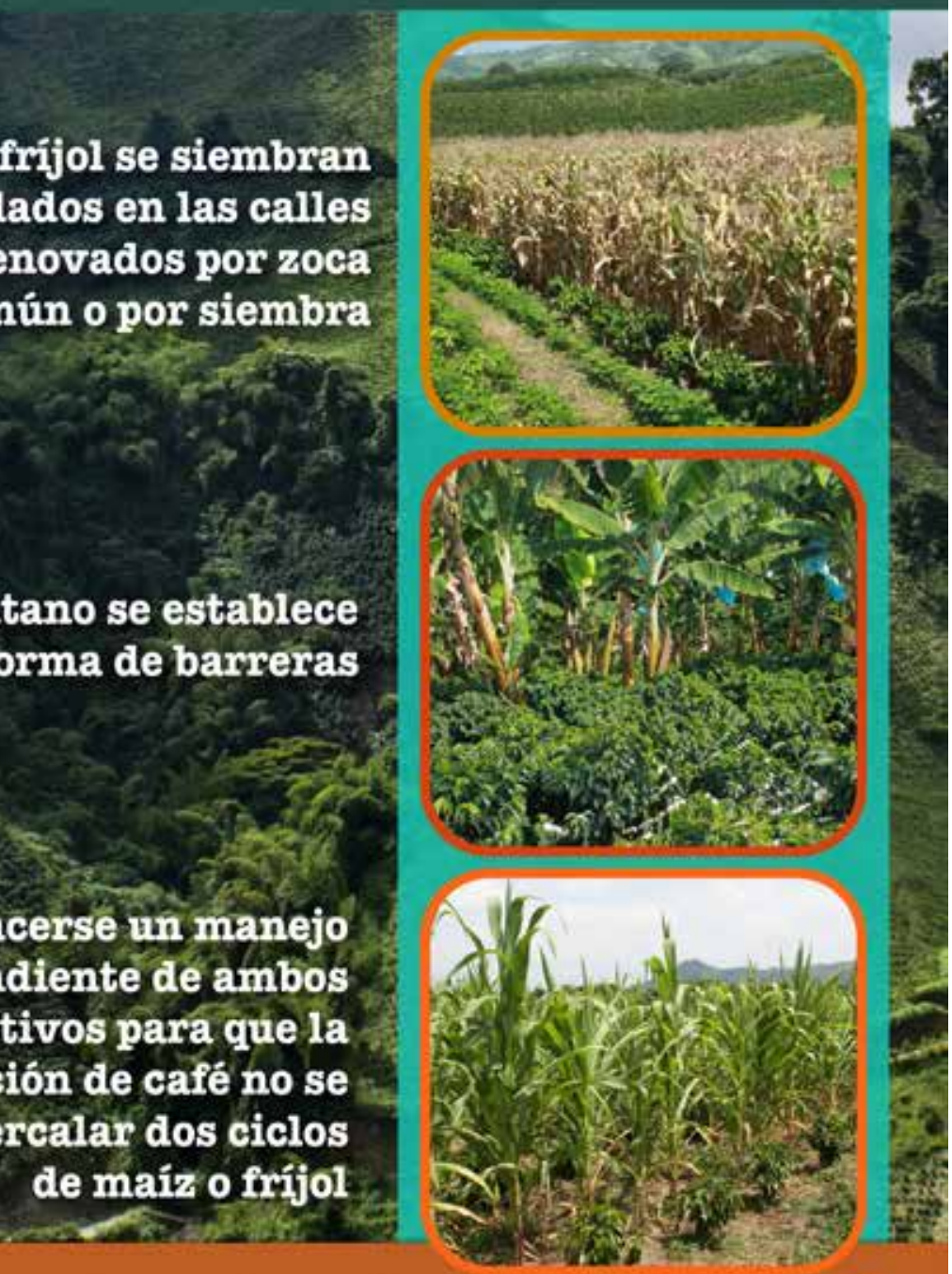

Para obtener una producción competitiva del café y del cultivo intercalado, planifieue la necesidad de mano de obra y el tiempo requerido para las labores de ambos cultivos consulte con su Extensionista

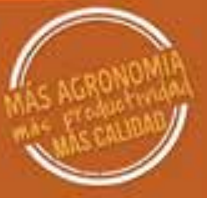




\section{Gultivos interballados GOn Geaf́̈}
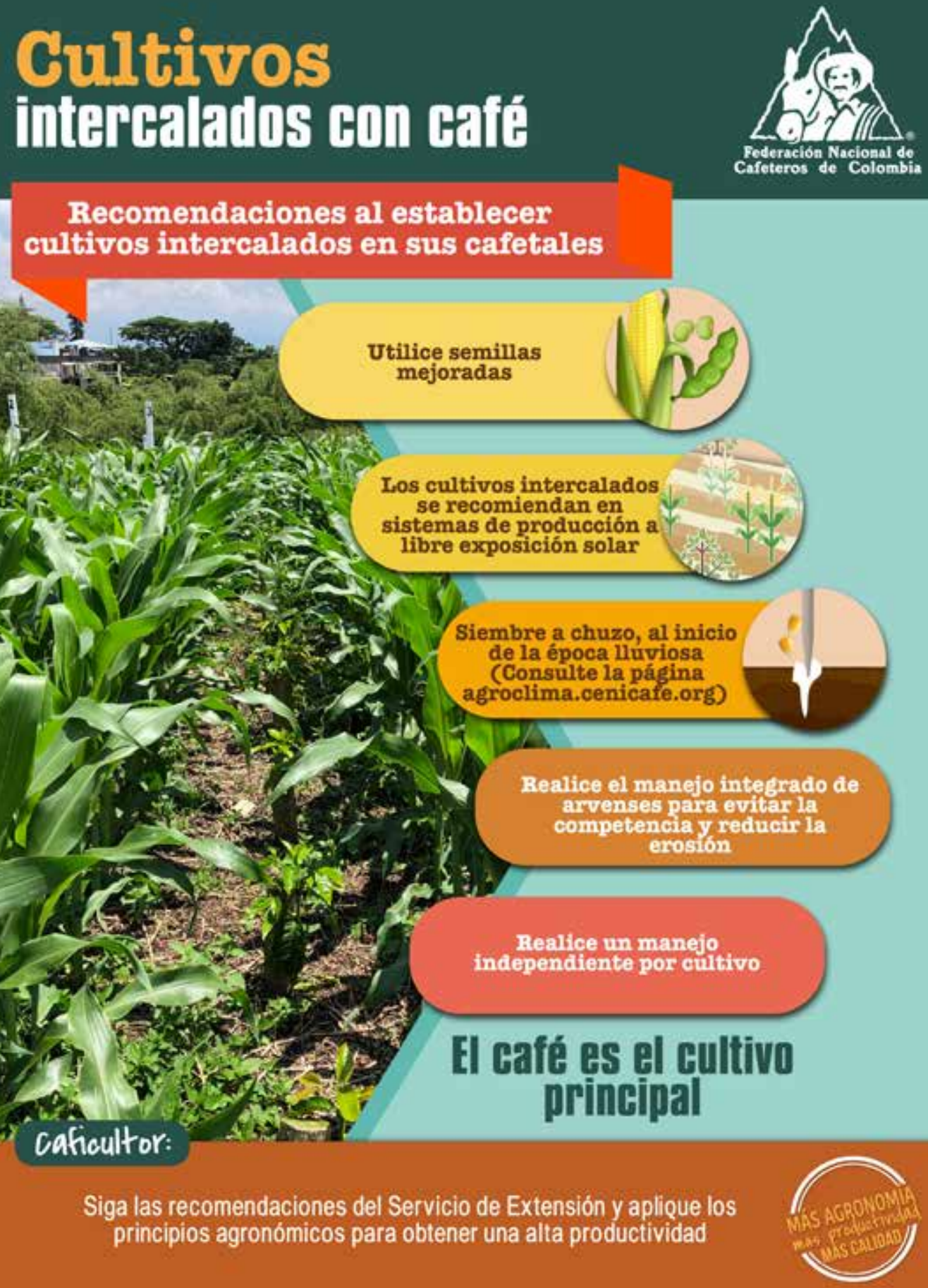


\section{Gultivos interealados GOn Baff́}

Ventajas durante la etapa de establecimiento del café

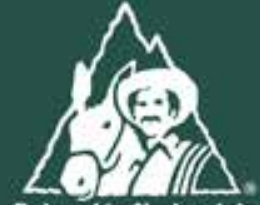

Federación Nacional de Cafeteros de Colombia

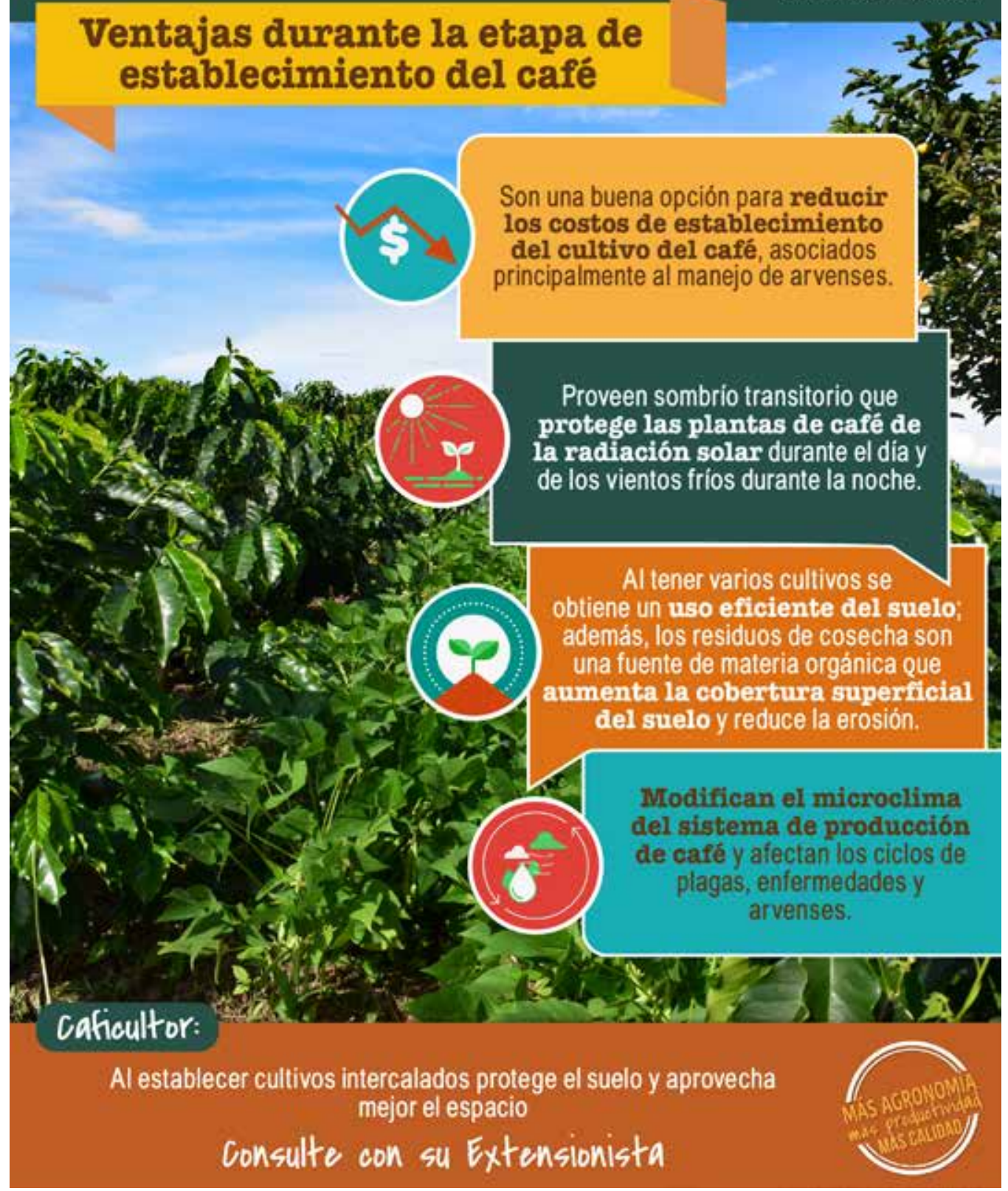

